\title{
CRÍTICA A LAS RESOLUCIONES DE LA CORTE CON RESPECTO A LA JERARQUÍA CONSTITUCIONAL DE LOS TRATADOS INTERNACIONALES*
}

\begin{abstract}
Arnau MURIÁ TUÑóN**
Resumen: El Pleno de la Suprema Corte de Justicia ha establecido para México la prelación de los tratados internacionales por encima de todas las demás fuentes normativas internas con la excepción de la Constitución federal. Aunque lo anterior responde a un reconocimiento del fenómeno de la "globalización" que debe ser abordado de alguna manera, se considera que el derrotero adoptado por la Suprema Corte es erróneo tanto por lo que respecta a su sustento argumental, pues parte de una serie de premisas que no podemos calificar sino de falsas, como por lo que hace a sus resultados, puesto que conllevan el riesgo de algunos efectos lesivos para nuestro orden político y constitucional. La Corte tiene a su alcance otros argumentos que le permitirían librar las situaciones que se pretenden salvar, pero con una argumentación más congruente y menores riesgos de desequilibrio constitucional.

ABSTRACT: The Supreme Court of Justice has held for Mexico the preemption of the international treaties over all the other internal sources of law except for the Federal Constitution. Although the afore decision is due to the recognition of the "globalization" phenomenon, that must be tackled somehow. It is considered that the holding adopted by the Supreme Court is a mistake both regarding its argument, since it departs from a series of fake assumptions, and regarding its results, since they entail a risk for some hazardous effect for our political and constitutional order. The Court had within its reach other reasoning that would have permitted to solve the issues that it intends to save but with a more congruent reasoning and less risk of constitutional turmoil.
\end{abstract}

RÉSUMÉ: La Court Suprême de Justice a établi pour Mexique la prélation des traites internationales sur toutes les autres sources normatives internes, avec l'exception de la Constitution Fédéral. Même si l'antérieur réponde à une recognition du phénomène de la globalisation, qui doit être aborde d'un manier. C'est considère que le chemin adopté par la Suprême Court est incorrect, par un côté pour le support des arguments qui part d'un série des prémisses qu'on peux seulement qualifie de faux, et en relation aux résultats car ils implique le risque de quelques effets lessives pour notre ordre politique et constitutionnel. La Court a dans son atteinte autres arguments qui le permettront sauver les situations qui se prétend sauver, mais avec une argumentation plus congru et moins risques de perdre l'équilibre constitutionnel.

* In memoriam Manuel Gutiérrez de Velasco.

** Profesor de la Universidad de Guadalajara. El autor de este trabajo quiere agradecer al personal de las bibliotecas del Palacio de la Paz en La Haya, la Universidad Pompeu Fabra, la Universidad de Buenos Aires y el Instituto de Investigaciones Jurídicas de la UNAM, por su desinteresada ayuda en la realización de este trabajo. 
SUMARIO: I. Introducción. II. Explicación del problema en términos generales y en referencia a nuestra realidad nacional. III. Solución de la Corte. IV. A manera de conclusión. Hacia una mejor solución por parte de la Corte.

\section{INTRODUCCIÓN}

Hace ya algunos años que el Pleno de la Suprema Corte de Justicia resolvió el caso de los controladores aéreos. La parte más trascendente de esta resolución fue un dictum $^{1}$ de la Corte, que sin ser necesario para resolver el caso concreto, estableció una tesis jurisprudencial que vino a señalar - de una manera precaria - la supremacía de los tratados internacionales sobre la legislación local y federal.

Ahora, con fecha 12 de febrero de 2007, el Pleno de Suprema Corte de Justicia volvió a tratar la cuestión y lo hizo en el sentido de confirmar el criterio que comenzó a establecerse en 1999. De esta sesión del Pleno resultaron tres tesis que tratan el tema de la jerarquía normativa, dos de ellas que aluden directamente a la cuestión de los tratados internacionales. Estas tesis, que más adelante transcribiremos, parecen muy desafortunadas, y no porque hayan sido redactadas con fecha martes 13, sino porque atentan claramente contra el orden constitucional del Estado mexicano; y del mismo modo que el primer precedente de 1999, resultan un golpe de Estado soterrado.

La decisión anterior reviste una enorme importancia en temas de derecho público y de derecho privado, y constituye una muy seria amenaza tanto para las legislaturas locales - competencia que se vería seriamente amenazada por la impronta federal en caso de seguir la tendencia - , como para el parlamentarismo mexicano, ya de por sí bastante menoscabado.

Este trabajo pretende analizar la lesión constitucional creada por la Suprema Corte de Justicia de la Nación al pretender solucionar de manera simplista la tensión entre la normativa interna y la internacional. Abordando en mayor medida el tema de la legitimación del menoscabo de las competencias de las entidades federativas y en una menor medida el menoscabo de la capacidad normativa del Congreso de la Unión como un todo y de la Cámara de Diputados en particular. No obstante abordar con mayor detalle la cuestión federal, consideramos que ambos problemas

1 Vocablo que se emplea para definir tomas de posición jurisprudenciales, cuando éstas no implican la ratio decidendi de la cuestión. 
tienen el mismo vicio de origen que es el demérito de los órganos primordialmente representativos del pueblo soberano.

La estructura del presente trabajo contiene en un primer apartado, una somera descripción de las tensiones naturales entre el derecho interno y el derecho internacional. Se pretende, de manera imparcial, concienciar al lector sobre los intereses en juego, haciendo el intento de aterrizar la discusión - un tanto abstracta - en la realidad nacional. En un segundo apartado se examina la resolución del Pleno de la Suprema Corte, y se pretende analizar las premisas falsas en las que basa sus argumentos, además se analizarán algunos de los posibles efectos lesivos de tal actitud de nuestro más alto tribunal. Finalmente, en el cuarto apartado, y a manera de conclusión, se expondrá la teoría de cómo se debió de abordar la cuestión, con las herramientas conceptuales y constitucionales al alcance de nuestro más alto tribunal.

\section{EXPLICACIÓN DEL PROBLEMA EN TÉRMINOS GENERALES, Y EN REFERENCIA A NUESTRA REALIDAD NACIONAL}

Originalmente, cuando se hablaba de tratados internacionales, el tema solía versar sustancialmente en lo referente a la suscripción de armisticios, alianzas, y si acaso para lidiar con cuestiones aduaneras. A partir de la Segunda Guerra Mundial, y sobre todo, a partir del advenimiento de la llamada globalización, los tratados internacionales comenzaron a versar cada vez más sobre temas internos de los Estados; involucrándose ya no cuestiones de guerra y paz, sino temas de educación, contratación pública, derechos humanos, medidas ambientales, estado civil, etcétera. "La globalización ha llevado a que esferas anteriormente consideradas de interés exclusivamente "doméstico", sean en la actualidad áreas de interés global, potencialmente regulables por fuentes de derecho internacional". ${ }^{2}$

El tema de la recepción de los tratados internacionales en los ordenamientos jurídicos internos ha sido ampliamente estudiado por la doctrina, su estudio desborda los objetivos de este modesto trabajo. En México, hemos soslayado analizar el porqué dichos tratados son únicamente ratifica-

2 Serna de la Garza, José María, El Poder de Celebrar Tratados Internacionales y la División de Competencias del Sistema Federal Mexicano, http://www.bibliojurídica.org/ libros/1/348/20.pdf (visto el 9 de mayo de 2007) p. 512. 
dos por el Senado y no por ambas cámaras del Congreso; pero más a aún se ha dejado de lado la interrelación de los tratados con el federalismo.

En los Estados federales o de estructura jurídica compleja con algún tipo de régimen parlamentario, este tema es a su vez susceptible de causar una serie de problemas de difícil resolución, toda vez que al tratar cada vez más sobre cuestiones de ámbito local, los tratados suscritos pueden llegar a menudo a invadir la esfera de competencia o soberanía de los estados o unidades territoriales que los integran, así como las facultades normativas de otros poderes como un todo, como es el caso en México del Congreso de la Unión.

Esta tensión entre las esferas locales y federales para el cumplimiento de los tratados internacionales no es un secreto. En 1951, un estudio de la UNESCO demostró que los Estados federales eran los más susceptibles de incumplir sus obligaciones internacionales para con dicha organización. ${ }^{3}$ De hecho, esta tensión entre las obligaciones de los Estados que suscriben tratados y sus impedimentos constitucionales, ha dado lugar a la práctica de incluir cláusulas federales en los tratados, en los que los mencionados Estados federales toman parte.

El dilema, que se da particularmente cuando se siguen las tesis monistas, deviene en uno entre el derecho constitucional de los Estados de estructura jurídica compleja o federales y el derecho internacional público.

En el derecho internacional público se considera la posibilidad de hacer tratados por parte de un Estado como entidad completa y suprema, ya que está establecido que precisamente es el Estado, el único competente para declarar la guerra y hacer la paz. ${ }^{4} \mathrm{~A}$ los ojos del derecho internacional, el compromiso del Estado federal prevalece sobre cualquier situación jurídica local, y si seguimos la norma tradicional, incluso sobre las disposiciones de derecho interno de los Estados, ¿también prevalecerá sobre las constitucionales? En la resolución actual de la Corte se ha determinado que éstas serían consideradas como meros hechos y no

3 Bernier, Ivan, International Legal Aspects of Federalism, Londres, Logman, 1973, p. 150.

4 Véase Wildhaber, Luzius, Treaty-Making Power and Constitution, Basilea, Helbing \& Lichtenhahn, 1971, p. 257. El autor ilustra perfectamente esta perspectiva realista de las relaciones internacionales convertida en principio jurídico. Este es el principio que tenemos que utilizar para lidiar con asuntos más tendientes a lo transnacional del DIPr. 
como normas. ${ }^{5}$ Por lo tanto, el Estado federal no puede descargarse de la responsabilidad de los actos de una de sus entidades. ${ }^{6}$

En cambio, si atendemos a un punto de vista estrictamente constitucional, tendríamos un dilema de difícil resolución.

Por un lado, si en un Estado de estructura jurídica compleja o con división de poderes se concediera a un poder la posibilidad irrestricta de suscribir los tratados que pasen por encima de las competencias estatales, se propiciaría, al menos sobre el papel, que se vaciara de contenido la cláusula residual o federal, que es la que establece la división entre las esferas de acción de los gobiernos centrales y estatales. Del mismo modo, si se concede a un poder una preeminencia sobre el poder que le sirve de contrapeso o se menoscaba la capacidad de decisión del poder que le sirve de contrapeso, también se podría llegar al efecto de vaciar, o menoscabar, la cláusula de división de poderes de la Constitución.

En contrapartida, si se impide a la Federación celebrar y/o cumplir tratados internacionales en tanto afecten las competencias locales, eso no implicaría que las unidades territoriales absorbieran las competencias para realizar tratados en las materias de su competencia; ya que, en una Federación, las entidades federativas tienen prohibido celebrar tratados de los que se deriven consecuencias normativas internas. Esta última situación generaría una laguna que no podría ser llenada por nadie, lo que resultaría inaceptable a los ojos del derecho internacional. ${ }^{7}$ Un efecto similar al que se produciría si se hicieran valer leyes del Congreso de la Unión en contra de tratados internacionales.

Esta tensión entre el poder normativo interno y el poder normativo internacional, puede dar lugar a escenarios que van desde generar una responsabilidad internacional de los gobiernos centrales por la actuación de los gobiernos locales ${ }^{8}$ o las legislaturas federales, hasta la declaración de inconstitucionalidad del tratado por parte de las autoridades competen-

5 Noción que ha sido atemperada en el artículo 46 del Convenio de Viena sobre Derecho de los Tratados, al permitir invalidar el tratado que atente contra la norma fundamental de un Estado.

6 Véase Wildhaber, op. cit., nota 4, pp. 266 y 267.

7 Ibidem, p. 257.

8 Véase infra "Caso Metalclad". 
tes, ${ }^{9}$ por un lado; ${ }^{10}$ o por el otro lado, a que se menoscabe un aspecto fundamental en la estructura federal como es la cláusula residual, ${ }^{11}$ y se destruya este sistema cuya premisa fundamental es el respeto a la esfera local, o en el ámbito puramente central, que se vacíe o menoscabe el contenido de la cláusula de división de poderes.

El dilema anterior deja de ser una cuestión meramente doctrinal, para pasar a ser una cuestión de una índole mucho más sustancial y de considerables repercusiones políticas y jurídicas. Tomemos en cuenta que dentro de un marco pluripartidista en los gobiernos estatales, se ha dado un incremento en cuanto a tratados internacionales suscritos con respecto a cuestiones de índole interior, lo que aunado a lo numeroso y lo diverso de las materias que dichos tratados llegan a abordar, provoca el riesgo de que las cláusulas residuales o federales sean vaciadas de contenido ${ }^{12} \mathrm{o}$ provocar que los tratados se invaliden o se incumplan.

En el campo del derecho internacional privado esta cuestión cobra una relevancia enorme, dado que pone en peligro a un sinnúmero de tratados y convenciones ${ }^{13}$ tendentes a regular el tráfico jurídico internacional de una manera más uniforme, necesidad cada vez más patente a consecuencia del incremento del tráfico jurídico internacional avenido a partir de la llamada globalización. Si habitar una aldea global con un reglamento de tránsito distinto para cada calle resulta muy complicado, ${ }^{14}$ más aún sería si una o varias de las calles tienen un reglamento distinto para cada cuadra.

Una resolución tajantemente federalista de cuestión podría dar al traste con esfuerzos conducentes a una mayor uniformidad en el trata-

9 Véase infra "Caso del Concordato".

10 Consecuencia que pudiera haberse derivado de la tesis P. C/92, "Leyes federales y tratados internacionales. Tienen la misma jerarquía normativa”, Semanario Judicial de la Federación, núm. 60, diciembre de 1992, p. 27.

11 Posibilidad existente, a partir de que la SCJN pronunciara la resolución del amparo en revisión 1475/98. Sindicato Nacional de Controladores de Tránsito Aéreo.

12 Véase Dehousse, Renaud, Fédéralisme et Relations Internationales, Bruselas, Bruylant, 1991, passim.

13 Existe un interesante artículo en el que se explica por qué las convenciones y los tratados deberán de tener un tratamiento equiparado en la jerarquía normativa constitucional. Véase Arteaga, Elisur, "Los tratados y las convenciones en el derecho constitucional”, Alegatos, México, núm. 10, septiembre-diciembre de 1988, pp. 127-135.

14 Gerold Hermann, cuando era secretario general de la CNUDMI, durante un ciclo de conferencias sobre dicha organización, Distrito Federal, 1999. 
miento de las situaciones de tráfico jurídico internacional, como los realizados por organismos tales como la Conferencia de La Haya sobre Derecho Internacional Privado, el Unidroit, La Comisión de las Naciones Unidas para el Derecho Mercantil Internacional (CNUDMI) ${ }^{15}$ y por la Organización de Estados Americanos a través de las Conferencias Especializadas sobre Derecho Internacional Privado (CEDIP). ${ }^{16}$

En dichos acuerdos, ya sea mediante el establecimiento de leyes uniformes, leyes modelos, y en casos más limitados, acuerdos generales o especiales sobre competencia judicial o legislativa internacional, pretenden facilitar un tráfico jurídico internacional con menos sobresaltos, mediante - siguiendo la metáfora anterior - la generación de un reglamento de tránsito armonizado para nuestra aldea global. Ya no digamos que una interpretación excesivamente federalista originaría un terrible daño a tratados en materia económica, como el TLCAN o el TLCUE; esto podría resultar catastrófico.

\section{Panorama nacional}

Por lo que hace a nuestro particular momento histórico en México, la política exterior mexicana a partir de los años ochenta sufrió su propia versión de la Perestroika; cambió de una postura un tanto xenófoba o proteccionista a una decidida política de apertura. Política que incluso, en ocasiones, ha sido calificada de "entreguista" por numerosos sectores del país. Independientemente de nuestros credos globalifílicos, globalifóbicos o globaliéticos, ${ }^{17}$ la realidad es que México en esta última etapa ha suscrito una buena cantidad de tratados internacionales que van bastante más allá de los asuntos ordinariamente cubiertos por el derecho internacional tradicional. Dichos tratados cumplen con finalidades mucho más tendentes a la interdependencia en la vida económica y social diaria de los habitantes del planeta que a las declaraciones de guerra, las alianzas $\mathrm{u}$ otras cuestiones que serían más a afines a la postura realista de las relaciones internacionales.

15 Son más utilizadas sus siglas en inglés Uncitral.

16 Estos últimos, un ámbito de vocación panamericana pero de realidad latinoamericana.

17 Véase Tunón, Arnau, “Globalifóbicos, globalifílicos y globaliéticos”, El Occidental, Guadalajara, 5 de septiembre de 2003, p. 6/A. 
Entre dichos instrumentos, cabe destacar que México, en estos últimos años, ha sido una parte muy activa en los organismos que buscan dar una mayor uniformidad en el tratamiento de las situaciones de tráfico jurídico y económico.

Las circunstancias anteriormente descritas por sí solas bastarían para complicar la cuestión. Empero, dado el mayor reparto de las posiciones políticas, debemos aseverar que en México se asiste actualmente a lo que podríamos llamar un "despertar constitucional" en el que debemos aplicar la Constitución y las soluciones institucionales a conflictos que durante los años del nacionalismo revolucionario en México podían ser resueltos, por lo que hacía al ámbito de lo público, e inclusive alguna vez en el privado, "en casa" por medio de la autocomposición dentro del marco de partido único, dándose con frecuencia soluciones que poco tuvieron de jurídicas. En cambio ahora, las crisis constitucionales son más susceptibles de generar verdaderos impasses que sólo podrían resolverse institucionalmente. Por lo anterior, debemos aceptar como una verdad sentada que la Suprema Corte de Justicia de la Nación y los tribunales federales están llamados a dar solución a numerosos problemas de esta índole.

Cabe tener en cuenta que el hecho de que los partidos únicos dañan los sistemas federales no es nuevo; ${ }^{18}$ mucho menos lo es que alteran el principo de división de poderes. Todas las instituciones constitucionales de un Estado tienden a ser soslayadas en regímenes poco plurales. Se ha llegado a considerar que los países con democracia precaria o inexistente favorecían tan poco la cuestión del federalismo, que cuando éstos acudían a la cuestión federal para no cumplir con algún tratado, se llegaba a considerar más como un pretexto que como cualquier otra cosa. ${ }^{19}$

Un claro ejemplo de cómo esta exacerbada internacionalización mexicana ha generado tensiones con los ámbitos locales, en un asunto mundialmente conocido: el "Caso Metalclad". En esa ocasión, México fue condenado en un arbitraje del Centro Internacional para el Arreglo de Diferencias sobre Inversión, debido una conducta ilícita para efectos del derecho internacional, pero difícilmente controlable por parte del gobierno del estado de San Luis Potosí y del municipio de Guadalcazar, que se negaron a permitir la operación de un centro de confinamiento de resi-

19 Véase Bernier, Ivan, op. cit., nota 3, pp. 5 y 6. 
duos peligrosos a una compañía estadounidense. De la lectura del laudo se desprende cómo el uso de facultades exclusivas del municipio de Guadalcazar fue lo que dio lugar a la reclamación. ${ }^{20}$

La Constitución Política de los Estados Unidos Mexicanos dice que los Estados Unidos Mexicanos son una Federación, conformada mediante un pacto federal celebrado por los diversos Estados libres y soberanos en cuanto a su régimen interior, que decidieron formar parte de la Unión, de ahí que se hable de que la Constitución contiene un pacto federal que, por otra parte, también dice que estamos en un régimen representativo y con división de poderes.

Mediante la técnica federal se formó una unión en la que los Estados cedieron una parte de sus competencias y facultades, es decir una porción de la autoridad soberana en ellos depositada por el pueblo, a una entidad supraestatal que es lo que conocemos como Federación. De esta manera, las facultades de la Federación quedaron claramente limitadas a aquellas que le habían sido cedidas por los Estados que la conformaron. Los Estados retuvieron todas aquellas facultades que no hubieran sido cedidas. ${ }^{21}$ Lo anterior quedó formulado en una cláusula residual que contenida en el artículo 124 de la Constitución expresa lo siguiente: "Las facultades que no están expresamente concedidas por esta Constitución a los funcionarios federales, se entienden reservadas a los Estados".

En menoscabo del federalismo, se ha argumentado que México proviene de un Estado unitario y que la Federación no fue sino una ficción jurídica. Sin embargo, la pretensión de que el federalismo deba contar con premisas justificativas para su adopción, consistentes en vigorosos regionalismos preexistentes, es falsa; porque si bien el federalismo sirve para centralizar poderes antes dispersos, como en Estados Unidos, también puede servir para descentralizar poderes anteriormente unificados, como en Canadá. ${ }^{22}$ Además, aunque se tratara de una ficción, sería una ficción que fue aceptada y acogida por el constituyente originario; si no se quiere vivir con las consecuencias de dicha ficción, para eso está el constituyente permanente.

En cuanto a la actividad referente a las relaciones internacionales, ésta fue otorgada por los estados a los órganos federales. Las posibili-

20 Caso ARB (AF)/97/1 CIADI. Bajado de la página en marzo de 2001.

21 Véase Tena Ramírez, Felipe, Derecho constitucional mexicano, pp. 101-127.

22 Ibidem, p. 108. 
dades de hacer la guerra, firmar tratados y establecer impuestos a las importaciones quedaron en manos de la Federación. Actividades que quedaron vedadas para los gobiernos estatales. ${ }^{23}$ Asimismo, en la Constitución se estableció que los tratados debidamente ratificados por el Senado que se ajustaran a la Constitución serían ley suprema de toda la Unión, quedando así por encima de todas las demás normas, incluyendo las estatales. ${ }^{24}$ Esta necesidad de respetar la Constitución nos remitiría al artículo 124 que señala la cláusula residual y al artículo 40 referente al régimen interior.

Mucho se ha discutido si las normas establecidas en los tratados internacionales prevalecerían, en caso de conflicto, por encima de las normas dictadas por las autoridades locales. Y dicha cuestión no ha sido privativa de México, sino que es una discusión recurrente en lo que se refiere a las relaciones internacionales de los diferentes Estados de estructura jurídica compleja o federales que figuran en la sociedad internacional.

\section{SOLUCIÓN DE LA CORTE}

La cuestión de la jerarquía de las diferentes normas en la pirámide normativa del sistema jurídico mexicano ha sido una cuestión discutida. ${ }^{25}$ Antes de 1999, los criterios de la Suprema Corte de Justicia de la Nación parecían establecer que para que una norma estuviera en concordancia con la Constitución, esta debería respetar los ámbitos estatales y municipales, fuera tratado internacional o ley federal, también establecía la igualdad normativa de las leyes federales y los tratados. Sin embargo, en 1999, la Suprema Corte mudó su criterio para establecer el siguiente criterio:

TRATADOS INTERNACIONALES. SE UBICAN JERÁRQUICAMENTE POR ENCIMA DE LAS LEYES FEDERALES Y EN UN SEGUNDO PLANO RESPECTO DE LA CONSTITUCIÓN FEDERAL. Persistentemente en la doctrina se ha formulado

23 Artículos 133, 117-I, 15, 89-X constitucionales.

24 Artículo 133 constitucional.

25 Siqueiros, José Luis, "Tratados internacionales. Se ubican jerárquicamente por encima de las leyes federales y en un segundo plano respecto de la Constitución federal", Revista Mexicana de Derecho Internacional Privado y Comparado, México, núm. 8, abril de 2000. 
la interrogante respecto a la jerarquía de normas en nuestro derecho. Existe unanimidad respecto de que la Constitución federal es la norma fundamental y que aunque en principio la expresión "serán la ley suprema de toda la Unión" parece indicar que no sólo la carta magna es la suprema, la objeción es superada por el hecho de que las leyes deben emanar de la Constitución y ser aprobadas por un órgano constituido, como lo es el Congreso de la Unión, y de que los tratados deben estar de acuerdo con la ley fundamental, lo que claramente indica que sólo la Constitución es la ley suprema. El problema respecto a la jerarquía de las demás normas del sistema, ha encontrado en la jurisprudencia y en la doctrina distintas soluciones, entre las que destacan: supremacía del derecho federal frente al local y misma jerarquía de los dos, en sus variantes lisa y llana, y con la existencia de "leyes constitucionales", y la de que será ley suprema la que sea calificada de constitucional. No obstante, esta Suprema Corte de Justicia considera que los tratados internacionales se encuentran en un segundo plano inmediatamente debajo de la ley fundamental y por encima del derecho federal y el local. Esta interpretación del artículo 133 constitucional, deriva de que estos compromisos internacionales son asumidos por el Estado mexicano en su conjunto y comprometen a todas sus autoridades frente a la comunidad internacional; por ello se explica que el Constituyente haya facultado al presidente de la República a suscribir los tratados internacionales en su calidad de jefe de Estado y, de la misma manera, el Senado interviene como representante de la voluntad de las entidades federativas, y por medio de su ratificación, obliga a sus autoridades. Otro aspecto importante para considerar esta jerarquía de los tratados, es la relativa a que en esta materia no existe limitación competencial entre la $\mathrm{Fe}-$ deración y las entidades federativas, esto es, no se toma en cuenta la competencia federal o local del contenido del tratado, sino que por mandato expreso del propio artículo 133 el presidente de la República y el Senado pueden obligar al Estado mexicano en cualquier materia, independientemente de que para otros efectos ésta sea competencia de las entidades federativas. Como consecuencia de lo anterior, la interpretación del artículo 133 lleva a considerar en un tercer lugar al derecho federal y al local en una misma jerarquía en virtud de lo dispuesto en el artículo 124 de la ley fundamental, el cual ordena que "Las facultades que no están expresamente concedidas por esta Constitución a los funcionarios federales, se entienden reservadas a los Estados". No se pierde de vista que en su anterior conformación, este Máximo Tribunal había adoptado una posición diversa en la tesis P. C/92, publicada en la gaceta del Semanario Judicial de la Federación, núm. 60, correspondiente a diciembre de 1992, p. 27, de rubro: "LEYES FEDERALES Y TRATADOS INTERNACIONALES. TIENEN LA MISMA JERARQUía NORMATIVA"; sin embargo, este Tribunal Pleno considera 
oportuno abandonar tal criterio y asumir el que considera la jerarquía superior de los tratados incluso frente al derecho federal.

Novena época, instancia: pleno, fuente: Semanario Judicial de la Federación, t. X, noviembre de 1999, tesis: P. LXXVII/99, p. 46, materia: constitucional, tesis aislada.

Amparo en revisión 1475/98. Sindicato Nacional de Controladores de Tránsito Aéreo. 11 de mayo de 1999. Unanimidad de diez votos. Ausente: José Vicente Aguinaco Alemán. Ponente: Humberto Román Palacios. Secretario: Antonio Espinoza Rangel. El Tribunal Pleno, en su sesión privada celebrada el veintiocho de octubre en curso, aprobó, con el número LXXVII/1999, la tesis aislada que antecede; y determinó que la votación es idónea para integrar tesis jurisprudencial. México, Distrito Federal, a veintiocho de octubre de mil novecientos noventa y nueve. Nota: Esta tesis abandona el criterio sustentado en la tesis P. C/92, publicada en la gaceta del Semanario Judicial de la Federación, núm. 60, octava época, diciembre de 1992, p. 27, de rubro: "LEYES FEDERALES Y TRATADOS INTERNACIONALES. TIENEN LA MISMA JERARQUÍA NORMATIVA".

En febrero de 2007, nuevamente la Corte trató la cuestión y dictó las resoluciones que en poco varían la resolución establecida en 1999.

TESIS AISLADA NÚM. VIII/2007 (PLENO) SUPREMACÍA CONSTITUCIONAL Y LEY SUPREMA DE LA UNIÓN. INTERPRETACIÓN DEL ARTÍCULO 133 CONSTITUCIONAL. A partir de la interpretación del precepto citado, si aceptamos que las Leyes del Congreso de la Unión a las que aquél se refiere corresponden, no a las leyes federales sino a aquellas que inciden en todos los órdenes jurídicos parciales que integran al Estado mexicano y cuya emisión deriva de cláusulas constitucionales que constriñen al legislador para dictarlas, el principio de "supremacía constitucional" implícito en el texto del artículo en cita, claramente se traduce en que la Constitución General de la República, las leyes generales del Congreso de la Unión y los tratados internacionales que estén de acuerdo con ella, constituyen la "ley suprema de la Unión", esto es, conforman un orden jurídico superior, de carácter nacional, en el cual la Constitución se ubica en la cúspide y, por debajo de ella los tratados internacionales y las leyes generales.

Amparo en revisión 120/2002. McCain México, Sociedad Anónima de Capital Variable. 13 de febrero de 2007. Mayoría de seis votos. Ponente: Sergio Salvador Aguirre Anguiano. Secretarios Andrea Zambrana Castañeda, Rafael Coello Cetina, Malkah Nobigrot Keinman y Maura A. Sanabria Martínez. 
TESIS AISLADA NÚM. IX/2007 (PLENO) TRATADOS INTERNACIONALES. SON PARTE INTEGRANTE DE LA LEY SUPREMA DE LA UNIÓN Y SE UBICAN JERÁRQUICAMENTE POR ENCIMA DE LAS LEYES GENERALES, FEDERALES Y LOCALES. INTERPRETACIÓN DEL ARTÍCULO 133 CONSTITUCIONAL. La interpretación sistemática del artículo 133 de la Constitución Política de los Estados Unidos Mexicanos permite identificar la existencia de un orden jurídico superior, de carácter nacional, integrado por la Constitución federal, los tratados internacionales y las leyes generales. Asimismo, a partir de dicha interpretación, armonizada con los principios de derecho internacional dispersos en el texto constitucional, así como con las normas y premisas fundamentales de esa rama del derecho, se concluye que los tratados internacionales se ubican jerárquicamente debajo de la Constitución federal y por encima de la las leyes generales, federales y locales, en la medida en que el Estado mexicano al suscribirlos de conformidad con lo dispuesto en la Convención de Viena sobre Derecho de los Tratados entre los Estados y Organizaciones Internacionales o entre Organizaciones Internacionales, y además atendiendo al principio fundamental del derecho internacional consuetudinario pacta sunt servanda, contrae libremente obligaciones frente a la comunidad internacional que no pueden ser desconocidas invocando normas de derecho interno cuyo incumplimiento supone además, una responsabilidad de carácter internacional. Amparo en revisión 120/2002. McCain México, Sociedad Anónima de Capital Variable. 13 de febrero de 2007. Mayoría de seis votos. Ponente: Sergio Salvador Aguirre Anguiano. Secretarios Andrea Zambrana Castañeda, Rafael Coello Cetina, Malkah Nobigrot Keinman y Maura A. Sanabria Martínez.

Como ya lo manifestamos arriba, esta resolución nos parece un auténtico despropósito y podría equipararse a un golpe de Estado soterrado. Creemos que los defensores de estas teorías dentro y fuera de la Suprema Corte de Justicia nos pretenden engañar, o por lo menos se engañan para justificar esta resolución, con una serie de premisas falsas tales como: a) Que el constituyente originario jamás atisbó la situación; b) Que en los países anglosajones así se resuelve; c) Que se trata de una obligación asumida por el Estado mexicano en su conjunto y que hay que cumplir con la Convención de Viena; que los Estados se encuentran representados en el senado; d) Que la cláusula residual no afecta a la cláusula de supremacía constitucional; e) Que el Pleno de la Suprema Corte puede decidir sobre cuestiones diferentes a la cuestión planteada.

Por otra parte, creemos que la resolución tiene los siguientes resultados lesivos para el sistema constitucional mexicano: a) Fortalecimiento del 
presidencialismo, en detrimento del parlamentarismo y en detrimento del federalismo, b) Ruptura del vínculo soberano de legitimación democrática, y c) Imposibilidad de dar marcha atrás.

A continuación abordaremos con un poco de mayor detalle, ambas cuestiones.

\section{Premisas falsas}

\section{A. Que el Constituyente originario jamás atisbó la situación}

Es casi un lugar común argumentar que al tiempo de la Constitución, los constituyentes no pudieron concebir un mundo en el que las normas internas estarían tan necesariamente vinculadas a las necesidades internacionales. Este ha sido un argumento recurrente de los que abogan por que los tratados internacionales pasen por encima de la legislación e inclusive las Constituciones estatales. El ministro Aguirre Anguiano hizo suyo este argumento cuando expresó los motivos de su resolución, también lo manifestó el ex presidente de la Corte Mariano Azuela Güitrón, cuando dijo "Probablemente en 1917, pues ni siquiera se les llegaba a plantear el problema". ${ }^{26}$ Lo anterior es parcialmente cierto, porque durante el siglo antepasado y principios del pasado, la nación sufrió una serie de intervenciones militares en la que países extranjeros utilizaron la llamada "diplomacia de la cañonera" para tutelar intereses de particulares en nuestro país y en muchos otros.

Esto originaría decisiones como establecer la Cláusula Calvo y otras más que para nada pretenden propiciar un acercamiento de los extranjeros ni de lo internacional en nuestro país, de hecho la Cláusula Calvo no era aceptada dentro del derecho internacional de su época ni fue aceptada después. Las bases históricas del nacionalismo revolucionario son precisamente las agresiones extranjeras que esgrimían el derecho internacional como la justificación de sus iniquidades.

26 Pero como se demuestra abajo, el tema no sólo se atisbó sino que se planteó, entonces tenemos un expresidente de Corte que no conoce el Diario de Debates de la Constitución de 1917, y lo que es más grave, que no lo consulta antes de emitir una opinión sobre la conformación de la Carta Magna. SCJN, Contenido de la Versión Taquigráfica de la Sesión Pública Ordinaria del Pleno de La Suprema Corte de Justicia de La Nación, celebrada 12 de febrero de 2007, p. 19. http://www.scjn.gob.mx/NR/exeres/CFDA98B8-D 422-4793-9F01-F679303BAEC5, frameless.htm. 
En este sentido, cabe apuntar que - durante los debates de la Constitución de 1917, al discutir el artículo 40 - se hizo patente la preocupación del Constituyente con respecto a la posibilidad de que el presidente abusara de las facultades en materia exterior, pudiera ceder demasiado hacia intereses extranjeros e incluso se propuso asentar que la soberanía seguía perteneciendo al pueblo. De hecho se ha señalado que el artículo 124 de la Constitución debe interpretarse en correlación con el artículo 40 del mismo texto. ${ }^{27}$

Otra observación que cabría hacer patente, es que en el caso no concedido de que la situación actual no pudiera ser concebida por el Constituyente originario, entonces tendríamos que asumir que no se dieron facultades al Senado y al presidente para violentar el orden constitucional. ¿Cómo puede presumirse que el Constituyente, en un régimen de facultades expresas, otorgó facultades a una o varias autoridades simplemente porque no podía concebir esta situación? En tal caso, la presunción debería ser la contraria, que el Constituyente no otorgó facultades para lidiar con una situación que no podía prever.

\section{B. Que en los países anglosajones así se resuelve, y que esa es la tendencia mundial}

En la resolución del amparo de los controladores aéreos se dice que:

Los países sajones, Inglaterra y los Estados Unidos, desde hace mucho tiempo son los que han aportado mayores luces jurisprudenciales a esta cuestión. Desde un principio priva la regla "the internacional law is part of the law of the land" (el derecho internacional es una parte del derecho del país). Es innegable que la tendencia mundial es la aceptación del derecho internacional como parte del interno y entonces, el problema se reduce más bien a determinar la forma en que las normas del derecho internacional se incorporan al derecho positivo de un Estado y a la jerarquía que éstas tienen en relación con la demás normas del sistema.

De dichas aseveraciones se desprende que, según lo que dijo la Corte, en los países anglosajones: a) El derecho internacional es una parte 
del derecho del país, y b) Que la tendencia mundial es la aceptación del derecho internacional como parte del interno.

En esta sentencia, los ministros olvidaron de un "plumazo" a la gran mayoría de los países anglosajones. Estos, al ser ex colonias británicas, parten todos y cada uno de una sentencia del Consejo Privado de su majestad británica que estableció el sistema de los compartimientos estancos, mismo que es seguido en cierta medida aún por Australia, Canadá, Nueva Zelanda e India. En dicho ordenamiento se entendía que el Estado nacional, en este caso la Corona británica, no podía realizar tratados sobre materias locales o domésticas sin el consentimiento de los implicados, es decir las legislaturas locales. Por consiguiente, si nos basáramos en el auténtico sistema anglosajón, el utilizado por Inglaterra, Australia, Canadá, India, Nueva Zelanda y todas las demás excolonias británicas, tendríamos que precisamente se siguen los principios contrarios al que pretende establecer la Suprema Corte.

Caso aparte serían los Estados Unidos, ahí el caso vigente es el caso Missouri $v$. Holland. ${ }^{28}$ Ahí se asentó que los tratados internacionales pasaban por encima de las legislaturas locales. En cuanto a la vigencia con las leyes del Congreso, se aplica el principio de lex posterior derogat lex anterior, sin embargo, este último aspecto del tema no es tan espinoso, porque para que un tratado entre en vigor se requiere una ley del Congreso que lo haga entrar en vigor, por lo que todas las preocupaciones que origina el fenómeno aquí en México, desaparecen.

Sin embargo, a raíz de Missouri se realizó la iniciativa de la Enmienda Briker a la Constitución americana, que aunque no entró en vigor, si ha hecho que las autoridades centrales sean muy cautas en materia de tratados. De hecho se ha llegado a sostener que Missouri $v$. Holland no es más que un fantasma. Toda vez que Estados Unidos ha argüido en repetidas ocasiones su incapacidad de entrar en tratados debido a que estarían invadiendo las facultades de los Estados. Tal es el caso de las Convenciones de la Organización Internacional del Trabajo en 1922,29 las Convenciones para la Supresión de Mujeres e Infantes de 1910 y 1921, etcétera. ${ }^{30}$

28 Henkin, Louis, Foreign Affairs and the U. S. Constitution, 1a. reimp. de la 2a. ed., N. Y., Oxford University Press, 1997, pp. 189 y 190.

29 En donde Estados Unidos luchó y consiguió una cláusula federal.

30 Wildhaber, Luzius, op. cit., nota 4, 1971, p. 335. 
Por otra parte, en el ámbito interamericano, en 1928 Estados Unidos se rehusó a adherirse al Código Bustamante ${ }^{31}$ de derecho internacional privado, dado que dichas cuestiones se dejaban por la Constitución al arbitrio de los Estados. Aunque por otro lado argumentaban que no la reconocían por utilizar una metodología jurídica continental en oposición a la metodología anglosajona; sin embargo, para entonces ya se había resuelto Missouri $v$. Holland, y todavía no se había dado la disputa por la enmienda Bricker, por lo que suponemos que era simple vociferación hipócrita a fin de reforzar su queja por no adoptar el Código la metodología angloamericana. ${ }^{32}$ Esta actitud se puede observar por parte del gobierno de los Estados Unidos de manera constante y repetitiva en cuando a las Convenciones Interamericanas. ${ }^{33}$

Por consiguiente, tampoco es cierto que la Sentencia de la Suprema Corte siga los principios de derecho anglosajón, ni es cierto que la tendencia mundial sea hacia el monismo, por lo menos no con los ejemplos que esgrimió la Corte. La Corte mintió.

Además, que la tendencia mundial vaya en uno o en otro sentido hoy en día, puede tomarse como motivo de pensar que la Constitución se redactó en ese mismo sentido, y a lo que debe de estar la Corte es a la voluntad del Constituyente.

\section{Que es una obligación asumida por el Estado mexicano en su conjunto, y hay que cumplir con la Convención de Viena}

El afirmar que los compromisos son asumidos por el Estado mexicano en su conjunto y que por eso son obligatorios para todas sus autoridades es una barbaridad, porque desde un punto de vista estrictamente constitucional, para que el Ejecutivo y el Senado hubieran podido obligar al Estado mexicano en un sentido o en otro, primero tendrían que haber estado facultados, dado que estamos en un régimen de facultades expresas en el que las autoridades no pueden hacer sino aquello que les está

31 Código de Derecho Internacional Privado propuesto por el jurista Antonio Sánchez de Bustamante y Sirvén, que fue adoptado por la Sexta Conferencia Panamericana celebrada en la Habana en 1928; véase Fernández Arroyo, Diego P., La codificación del derecho internacional privado en América Latina, Madrid, Eurolex, Monografías, 1994, pp. 123-158.

32 Véase Fernández Arroyo, Diego P., op. cit., nota anterior.

33 Véase la lista de tratados interamericanos de la OEA, http://www.oas.org. 
ordenado por la norma. En este caso, por la propia Constitución; lo cual no ocurre en ningún momento. ¿O en qué momento se les confirieron dichos poderes para obligar a las entidades federativas con respecto a su régimen interior? El artículo 40 constitucional parece sugerir lo contrario.

El ministro Cossío Díaz atacó dicho razonamiento en los siguientes términos:

Si bien es cierto que los tratados, desde el punto de vista del derecho internacional, sí vinculan al Estado mexicano en su conjunto, tal consideración no es valida en modo alguno para determinar la jerarquía de los tratados internacionales, lo que en esa resolución se presenta me parece, suma lo entendido entre estos dos aspectos, pues el hecho de que un Estado haya asumido un compromiso internacional con otros Estados, nada tiene que ver con la jerarquía normativa de ese tratado al interior de un orden jurídico, en tanto esa jerarquía sólo corresponde determinarla al orden jurídico de que se trate; así existen Constituciones, y mencioné alguna de ellas, en las que se determina que los tratados en determinada materia o todos ellos tendrán cierta jerarquía, misma que puede ir desde constitucional hasta la legal, de conformidad con las normas de cada uno de los ordenamientos. ${ }^{34}$

Por otra parte, si observamos la situación desde el punto de vista del derecho internacional público, tendremos que concluir cuando se realice un acto que entrañe una obligación hacía un Estado extranjero, éste podría muy bien ser exigible en el plano responsabilidad, y generar responsabilidad internacional por su incumplimiento, pero en ningún momento podría pensarse en que el mero acto de suscripción y ratificación permitiría modificar el orden jurídico interno.

Uno de los argumentos predilectos de los que abogan por la teoría de que son obligaciones asumidas por el Estado mexicano en su conjunto y que por ello los tratados internacionales pasen por encima de todas las demás normas de derecho interno, es en el sentido de que la propia Convención de Viena sobre Derecho de los Tratados establece en su artículo 53 que no se puede invocar una norma interna para incumplir un tratado. Citan que: "El hecho de que el consentimento de un Estado en obligarse por un tratado, haya sido manifestado en violación de una disposición de derecho interno concerniente a la competencia para celebrar tratados, no podrá ser alegado por dicho Estado como vicio de consentimiento, a me- 
nos que esa violación sea manifiesta y afecte una norma de importancia fundamental en su derecho interno".

El ministro Aguirre Anguiano, a quién le tocó ser el ponente de dicha resolución, de hecho se apoyó con vehemencia en dicho artículo y en dicha convención en su conjunto. De hecho en la tesis aislada número IX/2007 se invoca la Convención de Viena en los siguientes términos:

En la medida en que el Estado mexicano al suscribirlos de conformidad con lo dispuesto en la Convención de Viena sobre Derecho de los Tratados entre los Estados y Organizaciones Internacionales o entre Organizaciones Internacionales, y además, si atendemos al principio fundamental del derecho internacional consuetudinario pacta sunt servanda, contrae libremente obligaciones frente a la comunidad internacional que no pueden ser desconocidas invocando normas de derecho interno cuyo incumplimiento supone, además, una responsabilidad de carácter internacional.

Cabe apuntar que dicho argumento se viene presentando desde 1999, puesto que también se esgrimió en las páginas 97 a 99 de la sentencia que resolvió el caso de los controladores aéreos, y fue también apoyado por el ministro Mariano Azuela Güitrón.

Como bien lo señaló durante la discusión el ministro Cossío Díaz, se trata de un argumento circular, porque comienza apelando al carácter internacionalista y concluye con él. El argumento también es circular porque no se puede dar legitimidad a un tratado internacional dentro del orden constitucional mexicano, invocando otro tratado internacional, la validez o la invalidez de las normas en derecho mexicano; y me sorprende que esto sea ignorado en la propia Suprema Corte de Justicia, porque proviene fundamentalmente de la Constitución.

Por consiguiente, aseveraría que la validez constitucional de un tratado debe derivar de la propia Constitución y no de la interpretación de otro tratado. Tal razonamiento parecería poderse apoyar inclusive en la propia Convención de Viena sobre Derecho de los Tratados, puesto que, en su artículo 46, permite la anulación de un tratado por voluntad viciada cuando éste vaya contra la norma fundamental de uno de los Estados contratantes.

La postura simplista de derivar la validez de un tratado internacional fundamentándolo en la obligación del Estado como conjunto, también fallaría en explicar por qué en la práctica internacional del derecho de los tratados existe una gran cantidad de tratados internacionales con una 
cláusula federal; misma que permite a los Estados ir obligándose a cumplir con los tratados en la medida en la que sus unidades internas los vayan aceptando.

Además, en una interpretación más coherente de la Convención de Viena debería establecerse que la imposibilidad de invocar la violación de las competencias internas como causa de nulidad del tratado, es con el fin de impedir que ésta se invoque para evitar la responsabilidad internacional, producto de prometer lo que no se tenía, pero no con el fin de hacer forzosa su ejecución en el Estado parte. Esta última aseveración tendría su fundamento en el hecho de que ante la igualdad jurídica de los Estados - y éste sí es un principio de ius cogens, no lo que mencionó el ministro Aguirre-, el incumplimiento de un tratado internacional da lugar a la responsabilidad internacional, a la retorsión y las contramedidas, todas ellas a ser sufridas en primer lugar por el Estado en su conjunto, pero no da lugar en ningún momento al cumplimiento forzoso, que violentaría los órdenes competenciales internos.

En cambio, los que esgrimen estos argumentos se olvidan de la esencia del cumplimiento no forzoso de los tratados internacionales en contexto con la igualdad jurídica de los Estados. Otro cuestionamiento acerca de derivar constitucionalidad de la Convención de Viena devendría que de hecho en dicho instrumento, cuando un tratado se firma sin insertar la frase ad referéndum, se considera que el país está obligado al margen de la ratificación por sus órganos internos. Si el razonamiento de la Corte fuera correcto entonces los tratados podrían ser vigentes inclusive sin la ratificación del Senado, ya que la Corte pretende fundamentar la legitimidad de los tratados a partir de un tratado en sí.

\section{Que la Constitución mexicana es en esencia internacionalista}

El ministro Aguirre Anguiano aporta su nombre a la historia de la discusión de esta seria cuestión, agregando una más a la lista de las falacias que se esgrimen para fundamentar la superior jerarquía constitucional de los tratados. Este juzgador sostiene que nuestra "Constitución es internacionalista".

De hecho esta aseveración es llevada a la tesis de pleno IX de 2007 en cuanto que dice: 
La interpretación sistemática del artículo 133 de la Constitución Política de los Estados Unidos Mexicanos permite identificar la existencia de un orden jurídico superior, de carácter nacional, integrado por la Constitución federal, los tratados internacionales y las leyes generales. Asimismo, a partir de dicha interpretación, armonizada con los principios de derecho internacional dispersos en el texto constitucional... se concluye que los tratados internacionales se ubican jerárquicamente debajo de la Constitución federal y por encima de las leyes generales, federales y locales.

Durante la discusión, asevera el ministro que la Constitución Política de los Estados Unidos Mexicanos es internacionalista, porque en el artículo 3o. de la Constitución se establece la disposición programática de fomentar "el amor por la Patria y la conciencia de la solidaridad internacional" y sigue diciendo "esto es parte del sistema que se complementa con lo dicho por el artículo 15 constitucional, lo dicho por el 89, fracción $\mathrm{X}$, constitucional y lo dicho por el artículo 133 constitucional". 35

En lo concreto, el ministro Cossío Díaz rebatió de manera más adecuada la aseveración sobre el 3o. constitucional; dijo que la disposición se refiere a los planes y programas de estudios, que ésta es una disposición, pero que la jerarquía constitucional tiene poco que ver con la educación de los niños. Respecto a la fundamentación basada en el artículo $89 \mathrm{X}$, dijo que ningúno de los principios de política exterior ahí contenidos se refiere en forma directa a la jerarquía de los tratados.

No cuestionó el ministro Cossío Díaz la invocación del 15 constitucional, que contempla precisamente todo lo contrario, contempla límites a la posibilidad de celebrar tratados; no una corriente internacionalista sino más bien una corriente nacionalista. Tampoco nadie le cuestionó a Aguirre que en el propio artículo 3o. constitucional se establece que la educación "Será nacional, en cuanto - sin hostilidades ni exclusivismos - atenderá a la comprensión de nuestros problemas, al aprovechamiento de nuestros recursos, a la defensa de nuestra independencia politica, al aseguramiento de nuestra independencia económica y a la continuidad y acrecentamiento de nuestra cultura". Lo cual sí fue mencionado por el ministro Franco González Salas. ${ }^{36} \mathrm{Si}$ atendemos a estos principios - con la misma manga ancha que el ministro Aguirre Anguiano-, entonces la interdependencia económica planteada en los acuerdos 
económicos internacionales sería inconstitucional, y ya no se diga el pretender que los tratados internacionales pasen por encima de nuestras leyes.

Lo que aparentemente perdió de vista el ministro Aguirre Anguiano, y los que le ayudaron a redactar la sentencia, es en un sentido estrictamente jurídico: que el artículo 133 debe ser interpretado en consonancia con el artículo 40 y con el 124, tal y como lo establecen diversas constituciones comentadas.

Por otra parte, aseverar que la Constitución es internacionalista, entresacando unos artículos que como quedó demostrado nada favorecen la interpretación esgrimida, denota a la par de una seria incapacidad jurídica, una acusada parcialidad jurisdiccional y una terrible falta de formación histórica por parte de quien redactó la Sentencia y las tesis. Debemos recordar que la Constitución de 1917, lo que hizo fue establecer el ideario del nacionalismo revolucionario, mismo que de suyo siempre estuvo reñido con la injerencia exterior e históricamente rayó en lo xenófobo. Por lo tanto, decir que la Constitución mexicana es internacionalista no sólo es un error jurídico craso sino un embuste histórico flagrante. ¿En donde está el internacionalismo de la expropiación petrolera?

\section{E. Los Estados se encuentran representados en el Senado}

Este argumento que utilizó la Suprema Corte de Justicia de la Nación al resolver el caso de los controladores aéreos, es francamente endeble, lo que nos hace pensar que en el ánimo del que hizo la sentencia no había un gran convencimiento de los argumentos anteriores. Aquí la Corte intentó responder un cuestionamiento que para todos es posible realizar ¿Si los Estados quedan obligados, donde está su participación en los órganos que intervienen en el compromiso internacional? La corte respondió lo que sigue:

Esta situación se ve reforzada no sólo por la fuerza normativa que representan los compromisos internacionales, sino sobre todo por el hecho de que es suscrito por el presidente de la República en su carácter de jefe de Estado y la participación del Senado en el proceso, que como se mencionó representa la participación de las entidades federativas en el proceso de incorporación de un compromiso internacional al derecho positivo mexicano. 
Le negamos validez a este último argumento, porque el Senado se estableció originariamente para evitar que los estados más habitados "mayoritearan" a los estados menos habitados, pero nunca como una asamblea de "plenipotenciarios" tan dotados de autoridad que pudieran pasar por encima de sus legislaturas mismas. En ningún momento les fue concedida a los senadores la representación por parte de los estados para supeditar su orden interno y ni siquiera para obligarse en su nombre. A mayor abundamiento - inclusive si se aceptara la teoría de la representación de los senadores - me parece que no se podría, en este inconcedido caso, concebir que los estados cuyos senadores en cuestión votaran en contra, quedaran obligados. Al senado nunca se le invistió en la Constitución con el poder de modificar a su capricho el pacto federal ni como depositario de la porción de soberanía de la que, precisamente, son depositarios los estados.

Existe también un serio cuestionamiento por parte de Jorge Carpizo McGregor, quien en términos a la vez elegantes y moderados, dice: "El argumento de que el Senado representa a las entidades federativas está superado desde hace muchos decenios cuando las legislaturas locales perdieron la facultad de nombrar a los senadores, más hoy en día en que los senadores son electos a través de los principios de votación mayoritaria, primera minoría y representación proporcional". ${ }^{37}$

Efectivamente, coincido con el destacado jurista, porque si los senadores nombrados no podrían tener facultades para obligar a sus legislaturas, mucho menos así, los electos por mayoría proporcional.

Cabe explicar que este argumento no se reiteró durante las discusiones del 12 de febrero de 2007, sin embargo, no descartamos encontrarlo en el engrose, toda vez que en la tesis IX de 2007 se menciona que los tratados quedan por encima de las leyes locales. Sin embargo, el argumento sí fue atacado cuando el ministro Cossío Díaz atacó el argumento de que el Senado representaba a los Estados en los siguientes términos: "tampoco me parece que sea actualmente cierto, al menos desde las re-

37 Carpizo, Jorge, 'Los tratados internacionales tienen jerarquía superior a las leyes federales. Comentario a la tesis 192,867 de la Suprema Corte de Justicia de la Nación', en varios autores, "Tratados internacionales. Se ubican jerárquicamente por encima de las leyes, y en un segundo plano respecto de la Constitución federal (amparo en revisión 1475/98)", Cuestiones Constitucionales. Revista Mexicana de Derecho Constitucional, México, UNAM, Instituto de Investigaciones Jurídicas, núm. 3, julio-diciembre de 2000, consultado en http://www.juridicas.unam.mx/publica/rev/cconst/cont/3/cj/cj7.htm. 
formas constitucionales de agosto en 1996, pues los 128 integrantes del senado, no representan a los estados, representan a la población, en virtud de que se constituyen bajo principio de votación mayoritaria, primera minoría y representación proporcional". ${ }^{38}$

\section{F. Que la cláusula residual no afecta a la cláusula de supremacía}

Este argumento fue utilizado por la Suprema Corte en 1999 y no estamos exentos de que sea utilizado nuevamente en 2007, dado que como dije en el apartado anterior, la tesis IX de 2007 contiene la mención de primacía de los tratados por encima de las leyes locales. Este argumento, que está intimamente relacionado con el anterior, es quizá el más difícil de abordar y más o menos, dice:

Otra argumentación importante para considerar esta jerarquía de los tratados es la relativa a que en esta materia no existe limitación competencial entre la Federación y las entidades federativas, esto es no se toma en cuenta la competencia federal o local del contenido del tratado sino que por mandato expreso del propio artículo 133 el presidente de la República y el Senado pueden obligar al Estado mexicano en cualquier materia, independientemente que para otros efectos esta sea competencia de las entidades federativas.

Debe entenderse que la fórmula establecida en el artículo 124 constitucional sí alcanza a los tratados internacionales, cuando éstos afecten al interior de los Estados. Además debido a que es una redacción existente en la disposición rígida, a diferencia de la redacción existente en la disposición de Estados Unidos análoga en la Constitución estadounidense, no podemos considerar que la interpretación americana sea posible. La Suprema Corte de Justicia de la Nación no lo entiende así, aunque tampoco aportó mayores argumentos en apoyo de su tesis. Simplemente la dictó, sin explicar siquiera en la sentencia de dónde derivaría sus facultades el Ejecutivo para suscribir los mencionados tratados.

38 SCJN, Contenido de la Versión Taquigráfica de la Sesión Pública Ordinaria del Pleno de La Suprema Corte de Justicia de La Nación, celebrada el martes 13 de febrero de 2007, p. 58. http://www.scjn.gob.mx/nr/exeres/CFDA98B8-D422-4793-9F01-F6793 03BAEC5,frameless.htm. 
En su intento por encontrar disposiciones que fundamentaran la capacidad de la Presidencia de la República para, de manera conjunta con el Senado, obligar a los Estados, Serna de la Garza realizó un análisis de diversas disposiciones constitucionales para encontrar si existía algún fundamento en la Constitución que permitiera excluir las relaciones internacionales de la división de competencias establecida en el artículo 124 constitucional. ${ }^{39}$

Aunque los argumentos de Serna me parezcan complejos y elegantes, nosotros, por nuestra parte, debemos argüir que el artículo 124 debe interpretarse de manera conjunta con el artículo 40 constitucional, y que en dicho artículo se establece claramente la distinción competencial entre la Federación y los estados cuando dice que los estados son "libres y soberanos en todo lo concerniente a su régimen interior". Lo cual debe entenderse como que la soberanía correspondiente al régimen interior de cada Estado ha sido depositada por el pueblo en la Legislatura del propio estado. ${ }^{40}$ Lo interesante es que por un lado tenemos a un ministro que acude al artículo 3o. constitucional, en cuanto a que describe los planes de estudios para el sistema educativo nacional, para fundamentar su postura, y en un estudio "sistemático" se omite estudiar el 40 constitucional, cuando se analiza el 124 y 133.

En vista de lo anterior, un tratado que afectara disposiciones internas de un estado debería ser consentido por el representante del pueblo en esa entidad, puesto que los aspectos internos de la soberanía han sido depositados por el pueblo precisamente en las legislaturas de los estados, siempre y cuando no hayan sido cedidas por la propia Constitución a la Federación. Es de llamar la atención que pese a ser bastante claro que el artículo 40 debe venir a colación para interpretar la situación de referencia. ${ }^{41} \mathrm{El}$ que ni los doctrinistas, al interpretar la sentencia, ni la Suprema Corte, al dictarla, hayan tenido a bien siquiera mencionarlo, me hace creer que ante la incapacidad de encontrarle una cuadratura a este artículo dentro de su galimatías constitucional, los partidarios de esta sentencia

39 Serna de la Garza, José María, op. cit., nota 2, pp. 521-527.

40 Véase Rodríguez Lozano, Amador, "Comentario al artículo 40", en varios autores, Constitución Política de los Estados Unidos Mexicanos, comentada, 5a. ed., México, DF, PGR-UNAM, 1995, pp. 180 y 181.

41 Véase varios autores, op. cit., t. V, pp. 449-471, y t. VIII, pp. 799-810. 
optaron simplemente por correr un tupido velo y esperar enterrarlo en el olvido.

Mucho más contundente que las nuestras resultan las palabras del ministro Cossío Díaz al describir la posición de la mayoría:

Lo que tendríamos que concluir es que los tratados son de jerarquía superior a la Constitución, en tanto al celebrarse los mismos, no se está obligado a respetar la distribución competencial que la misma contiene, y esto mismo aplicaría respecto al artículo 26, que nos dice que ninguna disposición interna podría contraponerse al derecho internacional, pues eso significaría que todo el derecho internacional tendría jerarquía superior a la Constitución, porque si no se contrapondría, como lo anterior no parece ser el sentido que le asigne la Corte o le asignó a la jerarquía de los tratados, es necesario buscar otras soluciones.

\section{G. Que el Pleno de la Suprema Corte puede decidir sobre cuestiones diferentes a la cuestión planteada}

Del mismo modo que en la sentencia de los controladores aéreos, el Pleno se puso a discutir cuestiones que no eran necesarias para resolver la cuestión planteada. La sentencia que eliminaba la sindicalización única en las secretarías de Estado se podía sustentar perfectamente en el uso del artículo 5o. constitucional y la libertad de asociación. No obstante, la Corte estiró la litis planteada con el fin de poder abordar de una manera artificiosa por el modo, y a mi juicio desastrosa por los resultados, el tema de la jerarquía de los tratados, que vuelvo a decir, no era necesario tocar para resolver como se resolvió la cuestión solicitada. La Corte soterradamente se puso a legislar desde el banco del juzgador.

En 2007, sin embargo, excedió los límites al abordar temas de tratados de derechos humanos, mientras se discutían asuntos relativos al derecho económico. El excesivo uso de disquisiciones académicas y teóricas del que tanto se burlaron los ministros a lo largo del debate, no fue producto de que alguien quisiera jactarse de erudición, sino de que la propia Corte estaba saliéndose de su propio ámbito al pretender discutir el tema en lo abstracto y no en aplicación del caso concreto. Del mismo modo, el entrar a discutir el principio pro homine, relación de las leyes y Constituciones estatales y, en el más grave de los casos, reinventar el artículo 133, excedió por mucho la función jurisdiccional del Pleno de la Corte, puesto que ninguna de estas cuestiones venía a colación en una serie de 
casos que involucran cuestiones aduaneras y de comercio exterior, como en el caso concreto que llegó desde Guadalajara, la importación de maíz.

Esta vez, el constructivismo judicial se vio particularmente agravado por la llamada fragmentación de la decisión, mediante la cual se estableció que el pleno sólo establecería los principios y que las salas lidiarían con los asuntos específicos.

El Pleno, de manera sutil es cierto, asumió actitudes de legislador, puesto que los tribunales están para dirimir controversias concretas, no para fijar normas en lo abstracto. El fijar normas en abstracto le compete al legislativo y el discutir normas en abstracto, inclusive, a los académicos. Nos da la impresión de que la Corte está olvidando que su labor es resolver asuntos concretos y no legislar desde el banco del juzgador. No es de extrañar que la corte legisle mal, puesto que no está entrenada ni equipada para ello.

El presidente de la Corte, quien propuso que vieran en conjunto los asuntos que llegaron, y que discutieran en abstracto "el tema de la jerarquía normativa de los tratados internacionales", y que se reservara la jurisdicción a la Sala de su origen.

Después, el mismo presidente, al darse cuenta de que la resolución había sido votada en contra por la mayoría de los ministros de la Primera Sala, pidió que no abordaran de nuevo la cuestión dado que ya estaba resuelta en abstracto, y respecto a lo que se hizo dijo: "Esto es un escalamiento jurisdiccional inverso, le llamaría yo, y lo tenemos en otro sentido, cuando en amparo contra leyes, los jueces de Distrito, remiten en recurso de revisión a los tribunales colegiados y ellas resuelven todos los temas de procedencia, personería, legitimación, actos distintos a la ley impugnada, ejercen su jurisdicción en materia de su competencia y nos mandan a la Sala únicamente el problema de constitucionalidad". ${ }^{42}$

Por nuestra parte nos permitimos observar que si fuera así, sería completamente aceptable; pero aún cuando existen estos aspectos, el tribunal resuelve las cuestiones accidentales y la Sala (o el Pleno) las cuestiones esenciales, lo que olvidó el ministro presidente. Es decir que se resuelve el caso concreto y no se establece un principio en abstracto a manera de ley, lo que sería invadir la competencia del legislativo; y menos aún que se encargue después al inferior que analice el caso, y que se le diga que como ya dictamos la ley no alteras el principio establecido, 
porque violentaría la interpretación del caso abstracto. Aquí el Pleno de la Corte no sólo asumió el carácter de legislador, sino que también asumió el carácter de un legislador sin control constitucional, ni siquiera en vía de análisis de la cuestión completa.

\section{Efectos lesivos al orden constitucional de los Estados Unidos Mexicanos a los que podría llegar a dar lugar la resolución de la Suprema Corte}

Como se señaló, la decisión de la Corte es, en cuanto a los medios, bastante cuestionable; pero los resultados de una decisión como la actual también podrían redundar en severas consecuencias en el orden constitucional mexicano. De ahí que en ocasiones que, si tomamos las cosas con demasiado pesimismo, hablemos de un golpe de Estado soterrado.

La actitud de la corte probablemente redundará en un fortalecimiento del presidencialismo, en detrimento del parlamentarismo y del federalismo; mucho más grave tendrá el efecto de romper el vínculo de legitimidad democrática entre el ciudadano y las normas que lo rigen; y finalmente, dejará la vigencia de unas normas casi constitucionales, a perdurar a la entera voluntad del presidente.

\section{A. Fortalecimiento del presidencialismo en detrimento del parlamentarismo y del federalismo}

La norma establecida por el Pleno de la Suprema Corte es en detrimento del parlamentarismo, dado que le permitiría al presidente pasar por encima de cualquier disposición del Congreso como un todo con la sola aprobación del Senado, con sólo conseguir un estado "palero" que le firme un tratado; y que el Senado lo apruebe, se podría convertir en un superlegislador cuyas leyes pasarían por encima de todo. Claro está que el Senado podría oponerse, sin embargo, pensamos que el Senado por sí sólo es más débil ante la presión política del Ejecutivo aunado a los poderes e intereses extranjeros del Congreso de la Unión como un todo. Creemos que tratados como el TLC, por ejemplo, fueron una responsabilidad demasiado grande para que fuera asumida y limitada sólo por el Senado.

Un caso muy parecido a esto ocurrió en Estados Unidos para pasar por encima de las leyes locales. En Missouri v. Holland, la Federación no podía establecer una norma para proteger un ave migratoria. Ya había es- 
tablecido una ley federal que había sido impugnada con éxito por invadir una competencia federal, entonces se firmó un tratado con Canadá y se promulgó una nueva ley federal que ejecutaba el tratado. Resultado: la Corte de ese país decidió que aunque el tratado se hubiera realizado con la exclusiva intención de pasar por encima de la Legislatura local, era un tratado, y por consiguiente ley suprema de toda la Unión, esto generó una arrebatinga tal en el Congreso federal, que como resultado de esta situación, los Estados Unidos se abstienen casi siempre de invadir la competencia de sus estados cuando firman tratados, como ya se explicó arriba. No está demás recordar que los gobernadores de varios estados de la Unión Americana, entre ellos Texas, dijeron que la sentencia de la Corte Internacional de Justicia tal vez vinculaba a Estados Unidos, pero no necesariamente a Texas.

No vemos por qué no podría ocurrir algo así en México. Este sistema también podría aplicarse para pasar por encima de las legislaturas locales, y entonces favorecer no sólo al presidencialismo sino al centralismo. Es importante recordar que una de las maneras más efectivas de conservar la independencia de un país, es impedir que éste pueda ser controlado desde el exterior al controlar a un solo hombre.

Aquí la corte le dio un cheque en blanco al Poder Ejecutivo para voltear de cabeza, si quiere, el ordenamiento jurídico mexicano. Pasando por encima de dos principios fundamentales, el federalismo y la división de poderes.

\section{B. Hipotética ruptura del vínculo soberano de legitimación democrática}

En el artículo 39 constitucional se establece que la soberanía estriba en el pueblo, en el artículo 40 constitucional se establece que la organización de la república es representativa. Si el Senado representa a los estados y actualmente en gran medida a los partidos, tendríamos que entender que la representación del pueblo está en primer lugar en las legislaturas de los estados, y en segundo lugar, en las áreas que le fueron entregadas a la Federación por los estados al constituirse en una Federación, a la Cámara de Diputados del Congreso de la Unión.

Entonces, si se pretende permitir que el presidente con la aprobación del Senado, que es en un primer término representante de los estados (o más bien un agente de equilibrio para evitar que los estados despoblados 
se vean mayoriteados por los estados poblados) y en un segundo término representante de los partidos, pasa por encima del representante del soberano.

Porque hay que recordar que la obligación de todos nosotros de obedecer la ley, proviene del hecho de que es la decisión de nosotros como pueblo, por medio de nuestros legítimos representantes. Y los legítimos representantes del pueblo no son ni el Senado ni el presidente, son en sus respectivas materias las legislaturas estatales y la Cámara de Diputados del Congreso de la Unión.

Por lo que hace a violentar la cláusula residual establecida en el artículo 124, también es una aberración que nuevamente se explica con claridad meridiana mediante el artículo 40 constitucional, que ha sido soslayado durante todo este debate de constitucionalidad; y es muy claro. Se dice ahí que la Federación al conformarse se compone de estados libres y soberanos en cuanto a su régimen interior, pero que se unen a una Federación establecida según los principios de ley fundamental. Para darle un área competencial a la Federación, toda la Constitución describe cuáles son las competencias federales, y en el artículo 124 establece que las que no se comprendan como federales, son estatales, ¿por qué? Pues porque nunca fueron cedidas por los estados.

El régimen interior de los estados para cederlo en vía de tratados nunca fue cedido en ninguna parte de la Constitución. Además, cuando se redactó el artículo 133 no era imaginable que los tratados rigieran cuestiones locales o domésticas, por lo mismo tampoco es asumible que se dieron facultades a la Federación para tocar estas cuestiones porque simplemente no se sabía que se acostumbrarían a tocar algún día.

Si yo, antes de venir al Instituto de Investigaciones Jurídicas, digo en mi despacho "que nadie entre a mi oficina", a nadie se le va a ocurrir a mi regreso contestar: entré porque nunca dijiste que no entrara si algún día las cortinas eran moradas, y a mí me encantan las cortinas moradas.

Además, cabe recalcar que en el contexto del TLCAN tanto Canadá como Estados Unidos pusieron límites relacionados con sus estados durante la negociación. Por consiguiente nosotros somos los únicos "altruistas" que no contemplamos respetar nuestras propias instituciones frente a un tratado.

Por ello en caso de que un tratado internacional entre en conflicto con una ley del Congreso de la Unión o una ley local, el tratado estaría menoscabando la voluntad de la representación popular más auténtica 
con que cuenta nuestro sistema constitucional. No olvidamos que las diputaciones por representación proporcional también están presentes en dichos poderes, pero el menoscabo de esta figura constitucional a la representatividad de nuestros congresos es una discusión que supera por mucho el ámbito de este trabajo.

\section{Dificultad para "dar marcha atrás"}

Finalmente, quizá una de las partes más graves de la cuestión es que la única manera de quitarle los efectos a un tratado es denunciarlo, y la única autoridad que puede denunciar un tratado es el presidente de la República, por conducto o no de la Secretaría de Relaciones Exteriores. Entonces, en caso de que el presidente quisiera sostener un tratado por encima de la totalidad de la voluntad de la nación expresada por el Congreso de la Unión, sería imposible.

Tal parecía que los señores ministros al resolver la cuestión de los tratados internacionales, tenían tanta prisa por "bajarle los pantalones al país frente al extranjero que nunca previeron la manera de volvérselos a subir”, más que con la voluntad del presidente. ¿Cuál es la división de poderes entonces? ¿Cuál es el sistema de contrapesos entonces?

\section{A MANERA DE CONCLUSIÓN. HACIA UNA MEJOR SOLUCIÓN POR PARTE DE LA CORTE}

No nos oponemos a que los tratados internacionales que versan sobre cuestiones internas encuentren un cumplimiento. A lo que nos oponemos es a la antijuridicidad con que se buscó el resultado y la carencia de matices en el mismo.

A todos los que hemos estudiado con cierta profundidad el caso Marbury $v$. Madison nos sorprende la habilidad que desplegó el juez Marshall para extraer de una derrota en cuanto al caso concreto, una victoria a largo plazo al establecer el principio de la revisión judicial de las normas del Congreso. La Corte Americana aprovechó una derrota y un menoscabo a su autoridad para obtener una atribución mucho mayor a largo plazo.

En cambio, en este caso, la corte mexicana hizo gala de una visión obtusa: primero, en lo formal, "se brincó las trancas" al dictar una resolución materialmente legislativa para privar de facultades al Congreso de la 
Unión y a las legislaturas estatales; en segundo lugar, desaprovechó la oportunidad de tomar para sí la facultad de determinar, caso por caso, cuándo un tratado pudiera imperar por encima del ordenamiento interno, lo que además hubiera sido deseable. En este caso, la Corte hizo gala de prepotencia y arrogancia, metiéndose materialmente a legislar, para acabar por fortalecer al Ejecutivo en detrimento de los demás poderes, y a largo plazo en detrimento de la propia Corte como fiel de la balanza.

Si la corte hubiera atendido a los casos concretos, hubiera visto que nada le impedía determinar que en este caso los tratados debían de imperar. Hubiera podido establecer: 1) Que el incumplimiento del instrumento, en el caso concreto, pondría en peligro las relaciones comerciales de México, y 2) Que en razón de Lex especialis ${ }^{43}$ los tratados pasaban por encima de las leyes locales y federales porque en efecto trataban una cuestión internacional en su naturaleza, como es el ingreso de las mercancías o sus gravámenes o requisitos por ingresar. De esta manera, se hubiera retenido el control del presidente y la diplomacia mexicana impidiendo los efectos lesivos de una interpretación demasiado astringente del federalismo o el parlamentarismo. Pero no, los ministros prefirieron legislar en abstracto, que abordar caso por caso, y exhibieron lo que tendríamos que calificar como arrogancia pírrica, porque victoria no fue.

Este estándar no es nuevo, es una copia adaptada del estándar establecido por la Suprema Corte australiana para resolver el problema de los compartimientos estancos, planteado por el Consejo Privado cuando era Colonia, y así darle una autonomía mayor a la diplomacia australiana pero con cierta contención.

Otra observación extremadamente interesante es la aportada por Ligia C. González Lozano, durante una discusión en el seno de la Academia Mexicana de Derecho Internacional Privado, expuesta el 29 de marzo de 2007; dijo grosso modo que ante una norma que resultaría tener casi los mismos niveles que la Constitución, puesto que no se puede reformar fácilmente, esta debería de tener cuando menos algún límite. Que dado que el presidente protesta respetar la Constitución y que la Constitución establece en el artículo 89, fracción X, los principios de política

43 Tomamos este concepto de ley especial de la ponencia de Loretta Ortiz Ahlf en el seno de la Academia Mexicana de Derecho Internacional Privado, expuesta el 29 de marzo de 2007. 
exterior de México, por lo menos la actuación del presidente debiera de poder ser revisada al tenor de los mismos.

Si se aplicaran el estándar australiano combinado con la propuesta de Ligia C. González Lozano, tendríamos un excelente sistema que permitiría al Estado mexicano seguir actuando en el exterior, pero que también permitiría controlar la actuación de los órganos de la política exterior, a saber: presidente, Cancillería, Secretaría de Economía y Senado.

Si el Pleno de la Corte no se hubiera olvidado de que su función es juzgar casos concretos y no ponerse a inventar en abstracto el hilo negro en sesiones que más parecen pláticas de café para arreglar el mundo, hubiera tenido una posibilidad de atisbar una solución como la anterior o inclusive una solución muchísimo mejor.

En un país donde tenemos un dicho acerca de cómo es la policía china, tenemos que decir que la Corte fue grandilocuente pero poco profunda en su analisis de la cuestión planteada.

Finalmente, sólo me queda decir, como justificación al título de este trabajo, que en México se nos ha generado un problema, porque hemos suscrito un sinnúmero de tratados sin reparar en las consecuencias internas, pues "nos aventamos como el Borras", y además que la Suprema Corte de Justicia se ha puesto a realizar arreglos "chambones", como de mecánico de barrio, para darle vigencia y jerarquía interna a los tratados internacionales. 